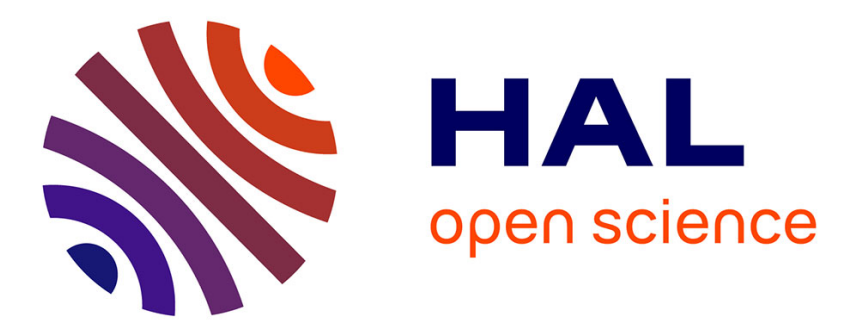

\title{
Viscoelastic modeling of wood in the process of formation to clarify the hygrothermal recovery behavior of tension wood
}

Marie Capron, Sandrine Bardet, K.C. Sujan, Miyuki Matsuo-Ueda, Hiroyuki Yamamoto

\section{To cite this version:}

Marie Capron, Sandrine Bardet, K.C. Sujan, Miyuki Matsuo-Ueda, Hiroyuki Yamamoto. Viscoelastic modeling of wood in the process of formation to clarify the hygrothermal recovery behavior of tension wood. Journal of Materials Science, 2018, 53 (2), pp.1487-1496. 10.1007/s10853-017-1573-9 . hal01662538

\section{HAL Id: hal-01662538 \\ https://hal.science/hal-01662538}

Submitted on 13 Dec 2017

HAL is a multi-disciplinary open access archive for the deposit and dissemination of scientific research documents, whether they are published or not. The documents may come from teaching and research institutions in France or abroad, or from public or private research centers.
L'archive ouverte pluridisciplinaire HAL, est destinée au dépôt et à la diffusion de documents scientifiques de niveau recherche, publiés ou non, émanant des établissements d'enseignement et de recherche français ou étrangers, des laboratoires publics ou privés. 


\title{
One-dimension visco-elastic modelling of wood in the process of formation to clarify the HygroThermal Recovery behavior of Tension Wood
}

\author{
Marie Capron · Sandrine Bardet · Sujan \\ K.C. · Miyuki Matsuo · Hiroyuki Yamamoto
}

\begin{abstract}
To explain the HygroThermal Recovery (HTR) behavior of Tension Wood (TW) from a physical and chemical point of view in relation to time, species and microfibrils angle (MFA), we made a theoretical discussion by using an analytical onedimensional visco-elastic modelling. The chosen model included an elastic element, a deformation mechanism and two visco-elastic elements also called Kelvin-Voigt model. In this analysis, a top-down approach between the model and the experimental data was introduced in order to find realistic parameters for the model. This made us possible to fit the model to the HTR experimental data for different species. The three species studied here are konara oak (Quercus serrata Murray), urihada maple trees (Acer rufinerve Siebold et Zucc.) and keyaki wood (Zelkova serrata Makino). The fitting experimental $d$ ata $s$ howed that $t$ he $t$ wo $c$ ompliances of the $t$ wo viscoelastic elements are the most important parameters that explain the evolution of TW longitudinal strain during the thermal treatment.
\end{abstract}

Keywords One-dimensional visco-elastic modelling · HygroThermal Recovery · Tension Wood · Green wood · G-fiber · Wood maturation

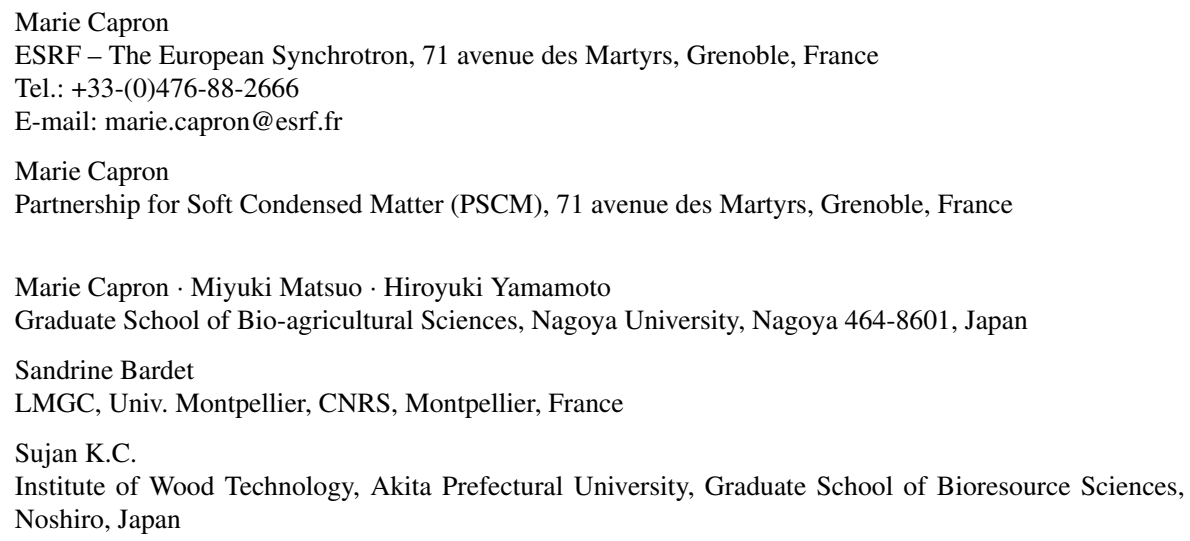




\section{Introduction}

Wood is produced by deposition of concentric layers at the periphery of the stem in an area called cambium. This production is going along with the setting up of growth stress. Growth stress has two origins: (1) loading, due to the weight of the structure, is applied progressively during the tree growth; (2) cell maturation, which happens at the end of the deposition of a new layer, causes a longitudinal (L) contraction (in the direction of the stem) and a tangential (T) expansion (tangentially to the growth rings), called maturation deformations. These deformations can't happen freely due to the previous layer and lead to the creation of initial tensile stress in $\mathrm{L}$ direction and compression stress in $\mathrm{T}$ direction [1] near the periphery. The formation of successive wood layers results in a growth stress distribution from pith to bark both in $\mathrm{L}$ and $\mathrm{T}$ directions. Furthermore, for inclined stems, or tree reorientation issues, specific growth stress is produced with a higher level of tensile stress in L direction in the case of broad-leaved trees. This particular wood with high longitudinal tension growth stress is called tension wood (TW) as distinct from normal wood (NW) and is generally characterized by an anatomical feature: the inside layer of tension wood cells is replaced by a thicker gelatinous layer called G-layer [2].

The study of longitudinal growth stress is of prime importance as it can generate severe problems during wood transformation, such as cracks or warping. It is especially crucial for high tensile stress in TW. Growth stress can be evaluated by measuring the locked-in strain which can be separated into two parts: instantaneous strain which is released by cutting wood specimens from the tree; while remaining viscous strain is enhanced by boiling green wood (never dried and freshly cut wood) above softening temperature of lignin [3]. This phenomenon is called HygroThermal Recovery (HTR) [4]. After the first thermal treatments, TW specimens undergoes longitudinal contraction, while NW specimens elongated slightly. For all type of wood, Sujan et al. [5] noticed a tangential elongation.

Growth stress can be approached from the point of view of the mechanical standing of trees as well as that of the loading history applied to the material before tree felling. Stress originates in wood maturation causing both stiffening and expansion to the cell-wall material. Gril et al. $[3,6]$ have done an uniaxial visco-elastic analysis on a portion of cylindrical stem on which the maturation of new layers is homogeneous on the periphery. They were studying an axisymmetric problem solved by a rheological analogy in parallel in which each element corresponds to one wood layer deposited on the periphery during the thickness growing.

Due to its polymeric semicrystalline nature, wood is a visco-elastic solid. The formation of cell wall layer used for building the tree skeleton is divided in several steps [7]: (1) building of the primary wall defining the outside boundary of the cells; (2) deposition inside of the cell of a cellulosic layer (secondary wall) at the same time, lignification happens in the primary wall; (3) maturation characterized by the lignification of the secondary wall, and, probably by the reticulation of the crystalline cellulosic filaments (microfibrils).The final step goes with the change of structure of the cell wall which has as consequence the transversally swelling of the cell and the 
axial shortening, in most of the case ; the rigidity increases [8,9]. Due to the fact that expansion is partially blocked while the cell walls are still soft induced deformations, the final rigidification will be mostly blocked. Clair [10] proposed a schematic model of L shrinkage. This model is used to explain the components of the shrinkage.

In order to better understand the establishment of growth stress due to the loading history during tree life, an one-dimensional ( $\mathrm{L}$ direction) rheological model of wood in the process of formation is proposed and used to simulate the Hygrothermal Recovery behavior of both tension and normal wood from a physical and chemical point of view. We propose in this study a top-down approach in which a model is fit to experimental data.

\section{Materials and methods}

The model was fitted on experimental data that have used three different species:

- one konara oak (Quercus serrata Murray), 52 year-old, diameter at breast height (DBH): $21 \mathrm{~cm}$, from Aichi Prefectural Forestry Research Center in Shinshiro, Aichi, Japan [5];

- two urihada maple trees (Acer rufinerve Siebold et Zucc.), 19 year-old, DBH: $10 \mathrm{~cm}$ and the other 21 year-old, DBH: $11 \mathrm{~cm}$, from the experimental forest of Nagoya University, Toyota, Aichi, Japan [5];

- one keyaki (Zelkova serrata Makino), age and diameter unknown, Japan.

The longitudinal axes experimental data have been used for the four samples. Lengths along the longitudinal axes of freshly sawn specimens were recorded at room temperature to determine the green-state dimensions, which served as the base values. These measurements were conducted in accordance with Tanaka et al. (2014) [11, 12], using a comparator with a precision dial gauge (reading accuracy, $0.001 \mathrm{~mm}$ ). The digital comparators and rectangular gage blocks as supporting boards were set on an iron surface plate so that all the specimens were at the same position for every measurements. Four different positions were measured.

The specimens of konara oak and urihada maple lay immersed in water while being heated, i.e., they underwent HT treatments for $10 \mathrm{~min}$ in an autoclave (Pasolina IST 150 , Japan) under $0.2 \mathrm{MPa}$ of pressure and a temperature of $120^{\circ} \mathrm{C}$.

Specimens of keyaki wood were grown in Japan, naturally dried after harvesting. The dimensions of the samples were approximately $25 \mathrm{~mm}(\mathrm{~L})$ x $6 \backsim 10 \mathrm{~mm}(\mathrm{R})$ x6 $\sim 10$ $\mathrm{mm}(\mathrm{T})$. (The average dimensions were $25 \mathrm{~mm}, 7.4 \mathrm{~mm}$, and $8.7 \mathrm{~mm}$ for $\mathrm{L}, \mathrm{R}$, and $\mathrm{T}$ directions, respectively.) The specimens were soaked in water for 3 days until they sank down. Wet specimens were boiled in water at $100^{\circ} \mathrm{C}$ for planned duration. $\mathrm{Cu}-$ mulative treatment durations were $0,5,10,15,25,35,50,100$, and 200 minutes.

After each hygrothermal treatment, all samples were immediately cooled by immersion in ice water, in order to lessen the effect of residual heat and arrest molecular activity within the wood. Then, length was re-measured at room temperature.

Surface growth stress is measured on living trees using strain gauges method [13], the highest value of tensile strain observed on the upper side of the tree stem gives the 


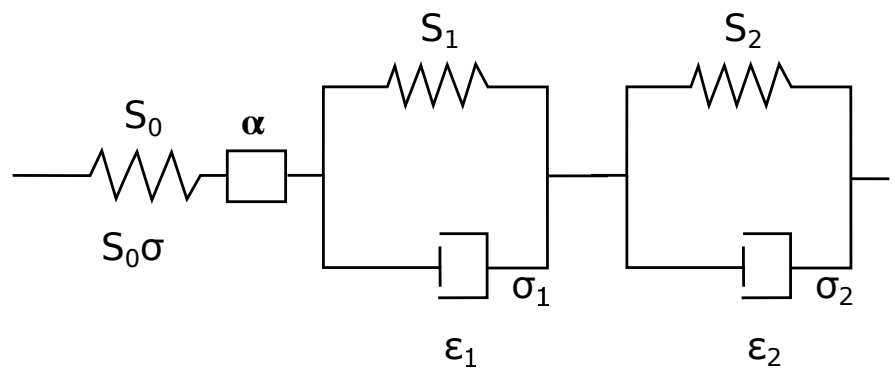

Fig. 1 Rheological analogy representing the model using of two visco-elastic elements with $\alpha$ the maturation strain, $S_{0}$ the elastic or mature compliance and $S_{1}$ and $S_{2}$ the delayed compliance.

tension wood zone, which is confirmed by an anatomical study of wood samples [5]. This allows to separate normal and tension wood samples before applying thermal treatment.

For each samples, the microfibril angle (MFA) has been measured in order to confirm the type of wood. MFA was measured using the X-ray diffraction (XD) technique on each specimen, as described by Yamamoto et al. (1993) [14,5].

\section{Analysis}

\subsection{Equation of the problem}

In order to model the maturation process, cutting and HygroThermal Recovery (HTR) of wood samples, a rheological analogy has been used (Fig. 1) [15,3]. This analogy is made of a serie of four elements:

1. an elastic element represented by a spring of compliance $S_{0}$ which is equal to that of mature wood;

2. a deformation mechanism representing the expansion tendency during maturation, with a varying strain $\alpha$;

3. two visco-elastic elements represented by a spring of compliance $S_{1}$ and $S_{2}$ in parallel with a dashpot also called Kelvin-Voigt model. The dashpot is considered either "soft", during the maturation process, or "hard" after the completion of maturation. The reason of the used of two visco-elastic elements will be explained in the Results and Discussion part.

The total strain $\varepsilon$ is the sum of the elastic strain $S_{0} \sigma$, the two viscous strains $\varepsilon_{1}=S_{1}\left(\sigma-\sigma_{1}\right)$ and $\varepsilon_{2}=S_{2}\left(\sigma-\sigma_{2}\right)$ and the maturation strain $\alpha$ :

$$
\varepsilon=S_{0} \sigma+\varepsilon_{1}+\varepsilon_{2}+\alpha
$$

In order to develop the viscous strains $\varepsilon_{1}$ and $\varepsilon_{2}$, the following equation was used for both viscous strains.

$$
\sigma_{i}=\eta \varepsilon_{i}
$$


In order to simplify the equation, the parameter $\tau_{1}=S_{1} \eta$ was introduced.

$$
\varepsilon_{1}=S_{1} \sigma-\tau_{1} \dot{\varepsilon_{1}}
$$

From the same method, we obtain a similar equation for $\varepsilon_{2}$.

$$
\varepsilon_{2}=S_{2} \sigma-\tau_{2} \dot{\varepsilon}_{2}
$$

with $\tau_{2}=S_{2} \eta$.

By using a Laplace transformation, we obtain, from the eq. 1, the differential equation of two Kelvin-Voigt in 1-D which will be used for modelling:

$\varepsilon+\left(\tau_{1}+\tau_{2}\right) \dot{\varepsilon}+\tau_{1} \tau_{2} \ddot{\varepsilon}-\alpha-\left(\tau_{1}+\tau_{2}\right) \dot{\alpha}-\tau_{1} \tau_{2} \ddot{\alpha}=\left(S_{0}+S_{1}+S_{2}\right) \sigma+\left(S_{1} \tau_{2}+S_{2} \tau_{1}+S_{0}\left(\tau_{1}+\tau_{2}\right)\right) \dot{\sigma}+S_{0} \tau_{1} \tau_{2} \ddot{\sigma}$

The model is divided in several steps. At the initial step $\left(t=t_{0}\right)$, we consider that the stress is null which means that in the equation [5]: $\varepsilon=0$. In this case, fibers are blocked and can not move.

The first step from $t_{0}$ to $t_{1}$ corresponds to the internal maturation and rigidification strain changes. The strain $\varepsilon=0$ is null during this step. During this first step, the function $\alpha$ varies from 0 to $\alpha_{\text {mat }}$ following equation 6 .

$$
\alpha(t)=\frac{a_{3}}{1+b_{3} \exp \left(-c_{3} t\right)}
$$

with $a_{3}, b_{3}$ and $c_{3}$ constants defined from the experimental data.

At the same time, the two functions $\tau_{1}$ and $\tau_{2}$ vary from 0 to their maximum values following sigmoid functions (eq. 7 and eq. 8), respectively. These two functions represent the rigidification of the wood sample.

$$
\begin{gathered}
\tau_{1}(t)=\frac{a_{1}}{1+b_{1} \exp \left(-c_{1} t\right)}+d_{1} \\
\tau_{2}(t)=\frac{a_{2}}{1+b_{2} \exp \left(-c_{2} t\right)}+d_{2}
\end{gathered}
$$

with $a_{1}, b_{1}, c_{1}, d_{1}, a_{2}, b_{2}, c_{2}$ and $d_{2}$ constants defined from the experimental data. An example of how the functions $\alpha, \tau_{1}$ and $\tau_{2}$ changes during the first step, are shown on figure 2 .

At $t=t_{2}$, the sample is cut. During the cutting, all the strain coming from the internal maturation strain changes is released. In order to represent this release in the model, the strain value at $t_{2}$ is equal to the opposite of the maturation strain value which corresponds to the value at $t_{1}\left(\sigma=-\sigma^{m}=-\sigma\left(t_{1}\right)\right)$.

The third and final step corresponds to the heating of the cut samples. In the case of heating, the strain is considered as null in the differential equation 5. And the heating is represented in the model as a decreased of $\tau_{1}$ and $\tau_{2}$ whereas the parameters 


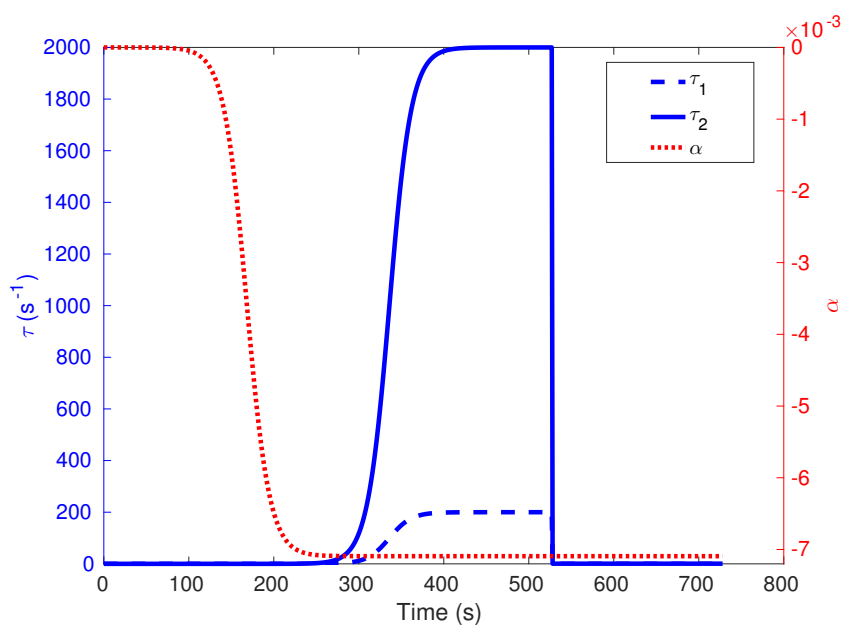

Fig. 2 Evolution during all the steps of modelling of functions $\alpha, \tau_{1}$ and $\tau_{2}$ as functions of time for Konara oak (Tension Wood)

$S_{0}, S_{1}, S_{2}$ and $\alpha_{m a t}$ are unchanged. This two functions $\tau_{1}$ and $\tau_{2}$ follow, respectively, equations 9 and 10 .

$$
\begin{aligned}
& \tau_{1}(t)=\tau_{1}^{H T R}+\left(\tau_{1}^{m a t}-\tau_{1}^{H T R}\right)\left(1-\exp \left(-k_{1}\left(t-t_{3}\right)\right)\right) \\
& \tau_{2}(t)=\tau_{2}^{H T R}+\left(\tau_{2}^{\text {mat }}-\tau_{2}^{H T R}\right)\left(1-\exp \left(-k_{2}\left(t-t_{3}\right)\right)\right)
\end{aligned}
$$

with $\tau_{1}^{\text {mat }}, \tau_{1}^{H T R}, k_{1}, \tau_{2}^{\text {mat }}, \tau_{2}^{H T R}$ and $k_{2}$ constants defined from the experimental data.

\subsection{Solving}

The model has been done using MatLab software and compared with Excel.

In order to solve this problem which includes two visco-elastic elements, a numerical discretization was used in which $\sigma(t)$ was hypothesized as linear on the step time [16-18]. So for $t \in\left[t_{i} ; t_{i+1}\right]$, we can write:

$$
\sigma(t)=\sigma\left(t_{i}\right)+\frac{\Delta \sigma}{\Delta t}\left(t-t_{i}\right)
$$

For each Kelvin-Voigt $(k)$, a combination of equations 11, 3 and 4 will give the differential equation of one Kelvin-Voigt $(k)$ :

$$
\dot{\varepsilon_{k}}=\tau_{k}^{-1}\left(t_{i}\right) S_{k}\left[\sigma\left(t_{i}\right)+\frac{\left(t-t_{i}\right)}{\Delta t} \Delta \sigma\right]-\tau_{k}^{-1}\left(t_{i}\right) \varepsilon_{k}
$$

The homogenous solution is:

$$
\varepsilon_{k}=C \exp \left(-\tau_{k}^{-1}\left(t_{i}\right) t\right)
$$


with $C$ a constant.

We are looking for a particular solution having the following form: $\varepsilon_{k}^{p}(t)=a+$ $b\left(t-t_{i}\right)$. In order to determine the value of $C$, we consider that at $t=t_{i}, \varepsilon_{k}^{V}\left(t_{i}\right)=$ $\varepsilon_{k}^{V}\left(t_{i-1}\right)$ which is the value obtained at the previous step time. The full solution of the differential equation 12 is then:

$$
\varepsilon_{k}^{V}(t)=\left[\varepsilon_{k}^{V}\left(t_{i}\right)-S_{k} \sigma\left(t_{i}\right)+\tau_{k}\left(t_{i}\right) S_{k} \frac{\Delta \sigma}{\Delta t}\right]+S_{k} \sigma\left(t_{i}\right)-\tau_{k}\left(t_{i}\right) S_{k} \frac{\Delta \sigma}{\Delta t} .
$$

From this equation 14, we can write the value of $\Delta \varepsilon_{k}^{V}$ :

$$
\begin{array}{r}
\Delta \varepsilon_{k}^{V}=\varepsilon_{k}^{V}\left(t_{i+1}\right)-\varepsilon_{k}^{V}\left(t_{i}\right) \\
=\left[\exp \left(-\tau_{k}^{-1}\left(t_{i}\right) t_{i+1}\right)\left[\exp \left(-\tau_{k}^{-1}\left(t_{i}\right) t_{i}\right)\right]^{-1}-1\right]\left[\varepsilon_{k}^{V}\left(t_{i}\right)-S_{k} \sigma\left(t_{i}\right)+\tau_{k}\left(t_{i}\right) S_{k} \frac{\Delta \sigma}{\Delta t}\right] .
\end{array}
$$

The detail of the different steps mentioned in the previous part is in the Appendix part.

\subsection{Parametrization}

The parameters of the model were defined as following.

From the modulus of elasticity $(M O E)$ at air dried condition found in the literature for Keyaki [19] or calculated by a density correction from Guitard's formula for Urihada and Konara [20], the Young modulus in green state $E_{L}$ can be defined from an empirical equation [21]:

$$
E_{L}(R H=30 \%)=E_{L}(R H=12 \%)(1-0.015(30-12)) .
$$

Above $30 \%$ of relative humidity $(\mathrm{RH}=30 \%)$, MOE are considered as constant with humidity.

The compliance $S_{0}$ is defined as the inverse of $E_{L}$.

From the fitting between the model and the experimental data, the ratio $R_{1}$ between $S_{1}$ and $S_{0}$ and $R_{2}$ between $S_{2}$ and $S_{0}$ are determined which allows the calculation of $S_{1}$ and $S_{2}$.

Concerning equation 9, $\tau_{1}^{\text {mat }}$ and $\tau_{1}^{H T R}$ are finding from the fitting. $k_{1}$ is equal to 1000 . The parameters of equation 7 are defined as followed:

$$
\begin{aligned}
& -\tau_{1}^{\text {completion }}=0.01 ; \\
& -a_{1}=\tau_{1}^{\text {mat }}-\tau_{1}^{\text {completion }} ; \\
& -b_{1}=\exp \left(-\left(1-4 \frac{t_{1}}{\Delta_{t_{1}}}\right)\right) \\
& -c_{1}=\frac{4}{\Delta_{t_{1}}}-\frac{1}{t_{1}} ; \\
& -d_{1}=\tau_{1}^{\text {completion }} \\
& -\Delta_{t_{1}}=50 \mathrm{~h} .
\end{aligned}
$$


For equation 10, the parameters are defined as follow: $\tau_{2}^{\text {mat }}=10 \tau_{1}^{\text {mat }}, \tau_{2}^{H T R}=10 \tau_{1}^{H T R}$ and $k_{2}=1000$.

The parameters of equation 8 are defined as followed:

- $\tau_{2}^{\text {completion }}=0.01$

$-a_{2}=\tau_{2}^{\text {mat }}-\tau_{2}^{\text {completion }}$

$-b_{2}=\exp \left(-\left(1-4 \frac{t_{1}}{\Delta_{t_{1}}}\right)\right)$;

- $c_{2}=\frac{4}{\Delta_{t_{1}}}-\frac{1}{t_{1}}$

$-d_{2}=\tau_{2}^{\text {completion }}$.

In the case of equation 6 , the parameters are:

$-a_{3}=-0.0024\left(1+R_{1}+R_{2}\right)$;

$-b_{3}=\exp \left(-\left(1-\frac{4 t_{1}}{\Delta_{t_{1}}}\right)\right)$;

$-c_{1}=\frac{4}{\Delta_{t_{1}}}-\frac{1}{t_{1}}$.

\section{Results and Discussion}

\subsection{Physical meaning of the model parameters}

In order to understand the purpose of using two visco-elastic elements in the model, a comparative study between model with one and two visco-elastic elements has been done with one set of Urihada maple data. In the case of one visco-elastic element, modelling equations 5, 8 and 10 are simplified considering that $S_{2}$ and $\tau_{2}$ are null in the parametrization. Figure 3 shows the fitting of one typical example of experimental data for tension wood. The one Kelvin-Voigt model is not enough to explain the decrease of the longitudinal strain over the time. Using one visco-elastic element model is needed but not enough to explain the effect of the temperature increase on the wood sample. This first model doesn't explain at all the end of the curve where the longitudinal strain is still decreasing with the time at the opposite of the model curve which is almost constant at the end.

Adding a second visco-elastic element in modelling allows a better fitting of the experimental data. This kind of model explains at the same time the effect of the increase of temperature which corresponds to the longitudinal contraction of tension wood after the first hygrothermal treatment. One possibility is that the repetitive change of temperature and moisture contents causes the increase of fibre saturation point (FSP) inducing the shrinkage of the G-layer. From this point of view, a two visco-elastic model corresponds to a first order chemical reaction [22]. A two viscoelastic elements model allows a correct fitting of experimental data and explains the different phenomena happening in the wooden sample during the thermal treatment. This model will be used for fitting all the experimental data of this study. 


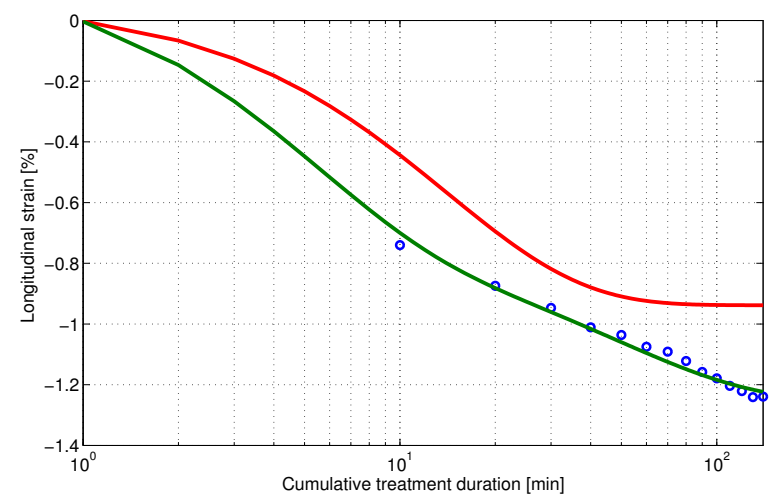

Fig. 3 Longitudinal strain changes as a function of cumulative treatment duration for Urihada maple (Tension Wood), experimental data (o) [5], modelling using 1 Kelvin-Voigt (-) and 2 Kelvin-Voigt (-)

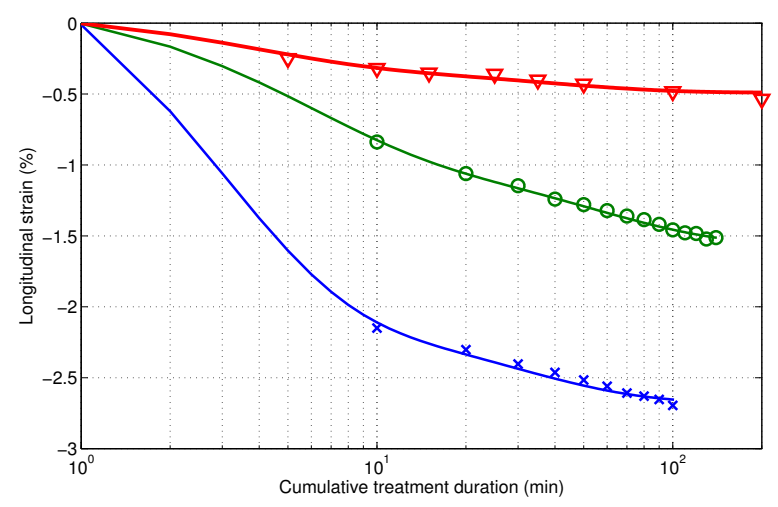

Fig. 4 Longitudinal strain changes as a function of cumulative treatment duration experimental data for Urihada maple (o), Konara oak $(\mathbf{x})$ and Keyaki $(\nabla)$ (Tension Wood) and their model using two visco-elastic elements (-).

\subsection{Comparison with the experimental data}

The same model has been used for tension wood and normal wood. Fig. 4 and Fig. 5 show longitudinal strain plotted against cumulative treatment period in typical respectively tension and normal wood for the three studied species. In the case of tension wood, specimens experienced significant longitudinal contraction after the first thermal treatment whereas normal wood specimens elongated slightly. The model allows to fit both behavior of tension and normal wood specimens during the instantaneous recovery phase and during the continuum contraction phase.

For each experimental data, a set of parameters has been obtained. The dependency of the four main parameters: $S_{1}, S_{2}, \tau_{1}^{\text {mat }}$ and $\tau_{1}^{H T R}$ has been compared to MFA because MFA provides a good evaluation of tension wood intensity of macro blocks 


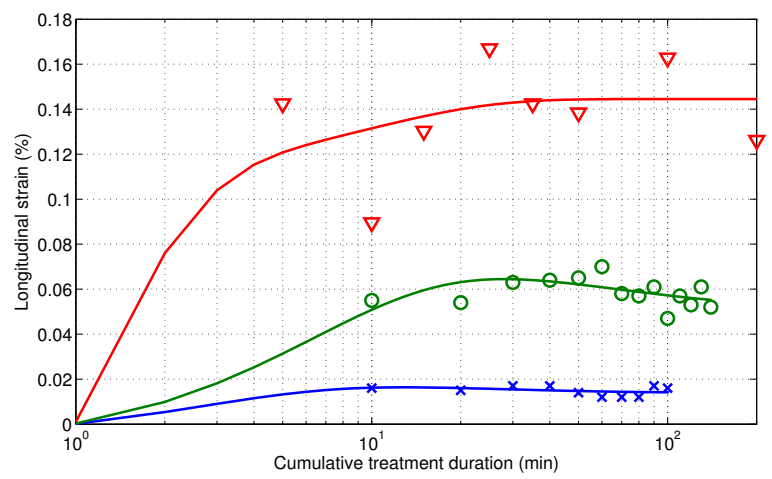

Fig. 5 Longitudinal strain changes as a function of cumulative treatment duration experimental data for Urihada maple (o), Konara oak (x) and Keyaki $(\nabla)$ (Normal Wood) and their modelling using two viscoelastic elements (-).

[23]. The figure 6 displays the dependency of $S_{1}$ on MFA for the three studied species for tension and normal wood. The first observation is that the dependency of $S_{1}$ on MFA is consistent between species even if the ratio of the G-layer to the cell wall are different between species. Indeed, Fig. 7 exhibits the signatures of the studied species in terms of G-layer thickness. Konara oak tension wood had a remarkably thick G-layer whereas urihada maple tension wood G-layer is thin. According to previous study [5], the dependency of MFA on the areal ratio of the G-layer apparently varied with each species. $S_{1}$ decreased with MFA from $8.9910^{-4}$ to $-1.6310^{-4}$ GPa. The dependency of $S_{1}$ on MFA is almost linear for tension wood which means for low MFA and almost constant for normal wood which corresponds to high MFA. The value of $S_{1}$ is positive for tension wood whereas for normal wood, this parameter is negative close to zero. This model can explain the behavior of tension wood. However for normal wood, it is almost impossible to find a physical explanation of the calculated negative compliance $S_{1}$ and $S_{2}$. As the values of $S_{1}$ and $S_{2}$ are close to zero, it could expressed a variation of this two parameters.

Concerning the parameter $S_{2}$ of the second visco-elastic element (Fig. 8), we observe a variation between $2.8310^{-4}$ to $-2.1110^{-5} \mathrm{GPa}$. This parameter is smaller than $S_{1}$. It can be explained by the fact that the second visco-elastic element is mostly used to fit the different phenomena happening in the wooden sample during the hygrothermal treatment. In this part of the curve, the decrease of the strain is less important than on the first part. $S_{2}$ is almost constant for very low MFA which corresponds to tension wood and for high MFA which corresponds to normal wood. The transition between tension wood and normal wood follows a step function.

The value of $\tau_{1}^{m a t}$ is almost constant between species and between tension and normal wood. The mean value of this parameter is for Urihada maple: $199.5 \pm 0.5$ $\mathrm{s}^{-1}$, for Konara oak: $199.9 \pm 4.10^{-3} \mathrm{~s}^{-1}$, for Keyaki: $199.9 \pm 9.10^{-4} \mathrm{~s}^{-1}$. This parameter was left free during the fitting part in order to check if it stayed constant. It is 


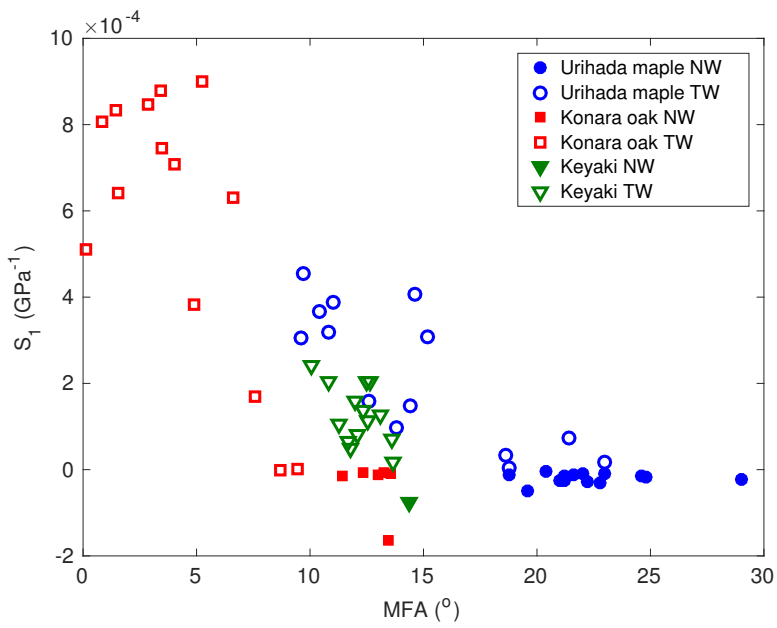

Fig. 6 The dependency of $S_{1}$ on MFA for normal and tension wood. $S_{1}$ is the spring of compliance of the first visco-elastic elastic elements.

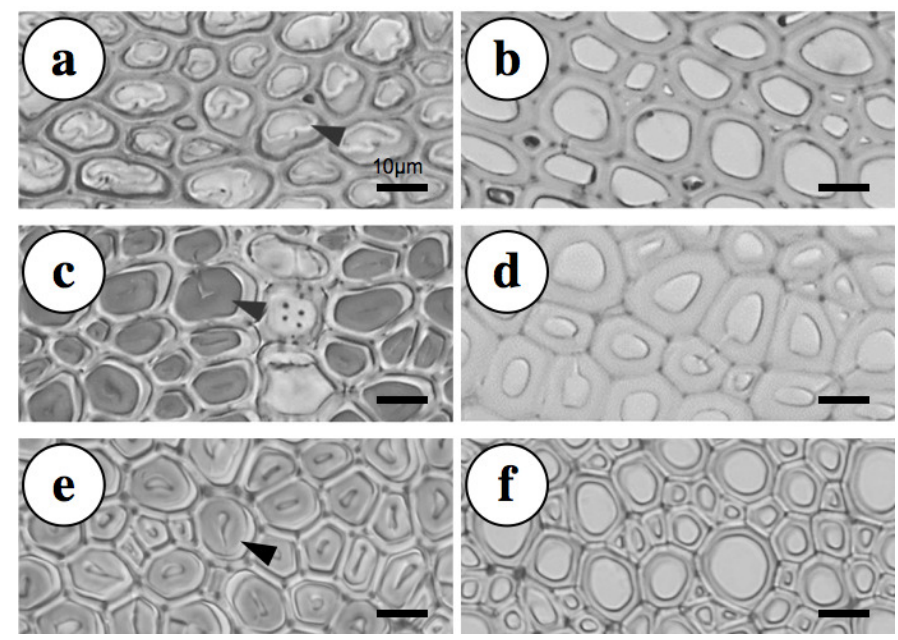

Fig. 7 Microscopic views of crosscut section of tested wood [5]. A: Urihada maple TW; B: Urihada maple NW; C: Konara oak TW; D: Konara oak NW; E: Keyaki wood TW; F: Keyaki wood NW. Scale bar is 10 $\mu \mathrm{m}$.

linked to the maturation of the wood and should not be affected by the type of wood (TW or NW).

The parameter $\tau_{1}^{H T R}$ (Fig. 9) increases with MFA but the variability is very high and the correlation is not very clear. This can be due to the fact that this parameter is linked to the amorphous part, called matrix, of the cell wall and so to its chemical composition. That can explain why this parameter behaves in the same way between 


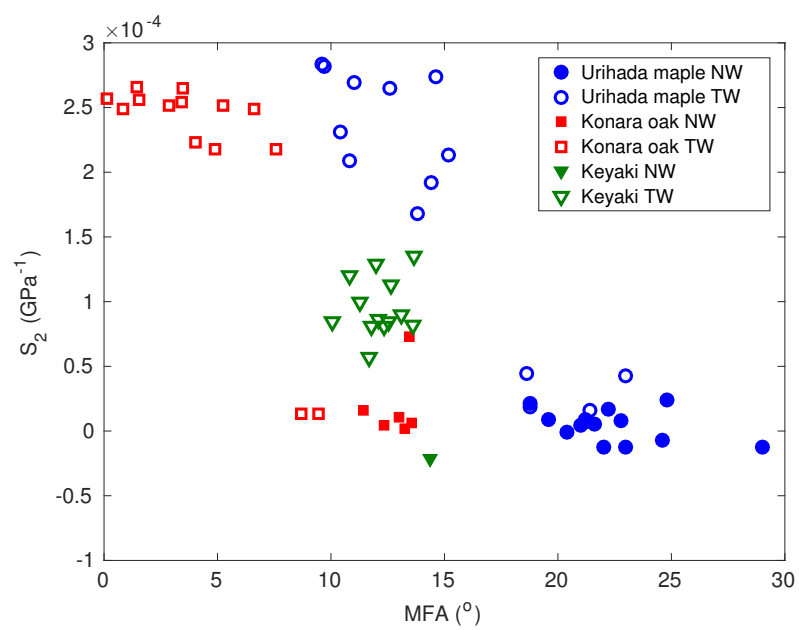

Fig. 8 The dependency of $S_{2}$ on MFA for normal and tension wood. $S_{2}$ is the spring of compliance of the first visco-elastic elements.

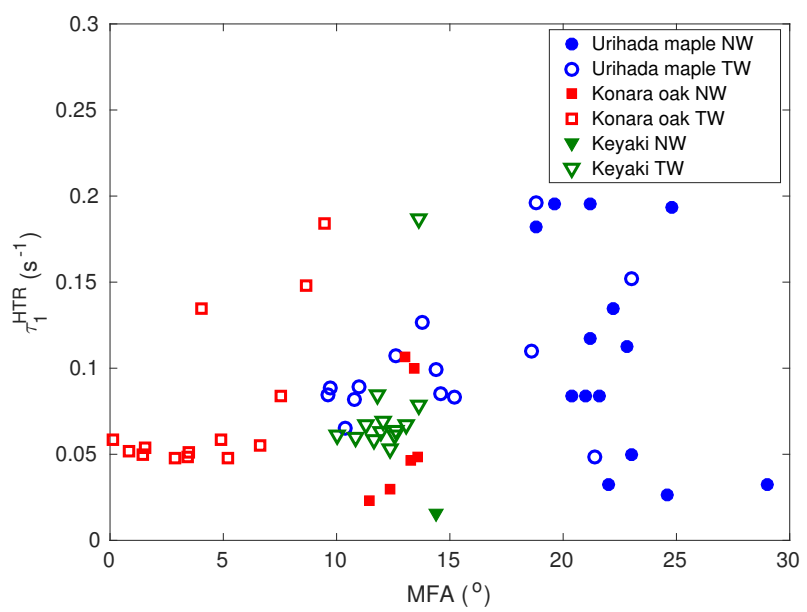

Fig. 9 The dependency of $\tau_{1}^{H T R}$ on MFA for normal and tension wood.

TW and NW. The parameter $\tau_{1}^{H T R}$ is still in discussion and remains less important that $S_{1}$ and $S_{2}$.

\section{Conclusion}

Experiments performed on Urihada maple, Konara oak and Keyaki wood allow to fit the developed one dimensional model of hygrothermal recovery. The chosen model included an elastic element, a deformation mechanism and two visco-elastic elements also called Kelvin-Voigt model. This model allows a fitting of tension wood sample 
which means samples with G-layer and with high longitudinal tension growth stress. This model helps us to clarify the effect of the increase of temperature corresponding to the longitudinal contraction of tension wood. The use of two visco-elastic elements allows the understanding of contraction of tension wood due to the repetitive change of temperature and moisture contents during the hygrothermal treatments. We have seen that a serie of four mechanical elements is needed to describe the elastic behavior of a TW sample, its deformation and its visco-elastic changes while it undergoes cutting and heat treatments.

The fitting with experimental data showed that the two compliances of the two viscoelastic elements are the most important parameters that the evolution of longitudinal strain during the hygrothermal treatment. The other parameters are linked to the internal chemical composition of wood cell wall.

The model can also fit normal wood with lignified fibers but it is almost impossible to explain the meaning of parameters especially the two compliance used in both viscoelastic elements which are negative. A new model for normal wood samples is now planned to understand the behavior of these samples during hygrothermal treatments.

Acknowledgements We would like to acknowledge the "JSPS International Research Fellows" who have support financially this work.

\section{References}

1. Archer RR (1986) Growth stresses and strains in trees. Springer Series in Wood Science - Hardcover

2. Onaka F (1949) Studies on compression and tension wood (translation from Japanese), Wood Research 1:1-88

3. Gril J and Thibaut B (1994) Tree mechanics and wood mechanics: relating hygrothermal recovery of green wood to the maturation process, Ann For Sci 51:329-336

4. Kubler H (1987) Growth stresses in trees and related wood properties, For Prod Abstr 10(3):61-119

5. Sujan KC, Yamamoto H, Matsuo M, Yoshida M, Naito K and Shirai T (2015) Continuum contraction of tension wood fiber induced by repetitive hygrothermal treatment, Wood Sci Technol 49(6):1157-1169

6. Gril J and Fournier M (1993) Contraintes d'élaboration du bois dans l'arbre: un modèle multicouche viscolastique, Actes du 11e congrès français de Mécanique (Lille-Villeneuve d'Ascq, France) 4:165-168

7. Terashima N (1990) A new mechanism for formation of a structurally ordered protolignin macromolecule in the cell wall of tree xylem, J Pulp Pap Sci 16(5):150-155

8. Alméras T, Gril J, Yamamoto H (2005) Modelling anisotropic maturation strains in wood in relation to fibre boundary conditions, microstructure and maturation kinetics, Holzforschung, 59(3):347-353

9. Yamamoto H (1998) Generation mechanism of growth stresses in wood cell walls: roles of lignin deposition and cellulose microfibril during cell wall maturation, Wood Sci Technol 32(3):171-182

10. Clair B (2012) Evidence that release of internal stress contributes to drying strains of wood, Holzforschung 66(3):349-353

11. Tanaka M, Yamamoto H, Kojima M, Yoshida M, Miyuki M, Abubakar ML, Ichiro H and Takeshi A (2014) The interrelation between microfibril angle (MFA) and hygrothermal recovery (HTR) in compression wood and normal wood of Sugi and Agathis, Holzforschung 68(7):823-830

12. Ueda Matsuo M, Niimi G, Sujan KC, Yoshida M and Yamamoto H (2016) Hygrothermal recovery of compression wood in relation to elastic growth stress and its physicochemical characteristics, J Mater Sci 51(17):7956-7965

13. Yoshida M, Ohta H, Yamamoto H, Okuyama T (2002) Tensile growth stress and lignin distribution in the cell walls of yellow poplar, Liriodendron tulipifera Linn., Trees 16(7):457-464

14. Yamamoto H, Okuyama T and Yoshida M (1993) Method of determining the mean microfibril angle of wood over wide range by the improved Caves method, Mokuzai Gakkaishi 39:375-381

15. Gril J (1992) Maturation and viscoelasticity: Rheology of wood in formation and hygrothermal recovery of growth strains, IUFRO All-division 5 conference (Nancy, France) 
16. Colmars J (2011) Hygromécanique du matériau bois appliquée à la conservation du patrimoine culturel. PhD Dissertation, Univ. Montpellier

17. Linard L (2011) Modélisation numérique tridimensionnelle du comportement viscoélastique d'un composite multicouche à base de bois. PhD Dissertation, Univ. Montpellier

18. Randriambololona H (2003) Modélisation du comportement différé du bois en environnement variable. PhD Dissertation, Univ. Limoges

19. Hirashima Y, Sugihara M, Sasaki Y, Ando K and Yamasaki M (2015) Strength Properties of Aged Wood III: Static and impact bending strength properties of aged keyaki and akamatsu woods, Mokuzai Gakkaishi 51(3):146-152

20. Guitard D and El Amri F (1987) Modèles prévisionnels de comportement élastique tridimensionnel pour les bois feuillus et les bois résineux, Annales des Sciences Forestières 44(3):335-358

21. Guitard D (1987) Mécanique du matériaux bois et composites. Cépaduès Editions

22. Sujan KC, Yamamoto H, Matsuo M, Yoshida M, Naito K, Suzuki Y, Yamashita N and Yamaji FM (2016) Is hygrothermal recovery of tension wood temperature-dependent?, Wood Sci Technol 50(4):759-772

23. Barnett JR and Bonham VA (2004) Cellulose microfibril angle in the cell wall of wood fibres, Biol Rev 79(2):461-472

\section{Appendix}

First case: $\varepsilon=0$

During the two first steps of the modelling, the stress is null $(\varepsilon=0)$. On a step time $\Delta t=t_{i}-t_{i-1}$, we can write that:

$$
\varepsilon=S_{0} \sigma+\alpha+\sum_{k} \varepsilon_{k}^{V}
$$

From this equation 17 , it is possible to write $\Delta \sigma$ :

$$
\Delta \varepsilon=S_{0} \Delta \sigma+\Delta \alpha+\sum_{k} \Delta \varepsilon_{k}^{V}
$$

In this case, $\Delta \varepsilon=0$, so we obtain:

$$
\Delta \sigma=S_{0}^{-1}\left(\Delta \alpha+\sum_{k} \Delta \varepsilon_{k}^{V}\right)
$$

with $\Delta \varepsilon_{k}^{V}$ from equation 15 .So the equation will be:

$$
\begin{gathered}
\Delta \sigma=\left[S_{0}+\sum_{k}\left[\left[\exp \left(-\tau_{k}^{-1} t_{i}\right)\left[\exp \left(-\tau_{k}^{-1} t_{i-1}\right)\right]^{-1}-1\right] \frac{\tau_{k} S_{k}}{\Delta t}\right]\right]^{-1} \\
{\left[-\Delta \alpha-\sum_{k}\left[\exp \left(-\tau_{k}^{-1} t_{i}\right)\left[\exp \left(-\tau_{k}^{-1} t_{i-1}\right)\right]^{-1}-1\right]\right]\left[\varepsilon_{k}^{V}\left(t_{i-1}\right)-S_{k} \sigma\left(t_{i-1}\right)\right] .}
\end{gathered}
$$

Using equation 19, we can write that $\sigma\left(t_{i}\right)=\sigma\left(t_{i-1}\right)+\Delta \sigma$. 
Second case: $\sigma=0$

During the fourth step of the modelling $\Delta \sigma=0$, equation 18 becomes:

$$
\Delta \varepsilon=\Delta \alpha+\sum_{k} \Delta \varepsilon_{k}^{V}
$$

with $\Delta \varepsilon_{k}^{V}$ from equation 15 .

Using equation 21 , we can write that $\varepsilon\left(t_{i}\right)=\varepsilon\left(t_{i-1}\right)+\Delta \varepsilon$. 